\title{
Upaya Peningkatan Pelayanan Administrasi Kependudukan Menggunakan Teknologi Informasi: Rancang Bangun Sistem Informasi di Desa Sumbermulyo Kecamatan Jogoroto Kabupaten Jombang
}

\author{
Moh. Anshori Aris Widya', Yosi Agustiawan², Ivan Dwi Fibrian², dan Zainal Muttaqin ${ }^{4}$ \\ 1,2,3,4 Sistem Informasi Fakultas Teknik Universitas Pesantren Tinggi Darul 'Ulum (Unipdu), Jombang \\ E-mail: ²yosiagustiawan@ft.unipdu.ac.id
}

\begin{abstract}
Abstrak
Desa adalah unit terkecil pemerintahan yang secara hukum diakui oleh pemerintah Indonesia. Salah satu tugas pemerintahan desa adalah memberikan pelayanan administrasi kepada penduduknya. Akan tetapi, pelayanan ini masih belum sesuai dengan harapan masyarakat karena aparat desa masih menggunakan cara manual untuk mengolah data. Penelitian ini berupaya untuk mencari solusi untuk meningkatkan pelayanan administrasi di Desa Sumbermulyo, khususnya masalah kependudukan. Dari hasil penelitian, Desa Sumbermulyo membutuhkan sistem informasi untuk mempermudah pengolahan data kependudukan. Untuk itu sebuah sistem administrasi kependudukan dibuat dengan menggunakan bahasa pemprograman Microsoft Visual Basic.Net 2008 dan sistem manajemen basis data MySQL untuk pengolahan datanya. Perangkat lunak ini mampu menghasilkan aplikasi berbasis grafis dan berjalan di sistem operasi Windows. Oleh karena itu, sistem informasi diharapkan akan mudah untuk diterapkan dan digunakan oleh aparat desa.
\end{abstract}

Kata kunci: Administrasi Desa, Microsoft Visual Basic.Net 2008, Sistem Informasi.

\begin{abstract}
A Village as the smallest unit of authority which is legally recognized by Indonesian government obligated to serve its citizens. Unfortunately, public administration, especially demographic data, in Desa Sumbermulyo is very poor since its officers remain use manual procedure in daily services. This research found that Desa Sumbermulyo requires improving its services through information sytem implementation. Microsoft Visual Basic.Net 2008 and MySQL software can be utilized to create public administration information sistem. These software are be able to produce an application based on graphical user interface (GUI) and run in Windows operating sistem. Therefore, that information sistem will be simple to implement as well as simple to use.
\end{abstract}

Keywords: Microsoft Visual Basic.Net 2008, MySQL, Information Sistem, Public administration.

\section{Pendahuluan}

Desa adalah unit administrasi pemerintahan terkecil di Indonesia. Undang-Undang No 6 Tahun 2014 tentang Desa menyatakan bahwa (Indonesia, 2014):

"Desa adalah desa dan desa adat atau yang disebut dengan nama lain, selanjutnya disebut Desa, adalah kesatuan masyarakat hukum yang memiliki batas wilayah yang berwenang untuk mengatur dan mengurus urusan pemerintahan, kepentingan masyarakat setempat berdasarkan prakarsa masyarakat, hak asal usul, dan/atau hak tradisional yang diakui dan dihormati dalam sistem pemerintahan Negara Kesatuan Republik Indonesia".

Salah satu tugas pemerintahan di tingkat desa adalah melaksanakan pelayanan administrasi yang dibutuhkan oleh masyarakat. Agar pelayanan ini dapat berjalan maksimal, desa dikepalai oleh kepala desa dan perangkat desa, serta lembaga lain yang dibentuk menurut kebutuhan desa sesuai dengan Undang-Undang Republik Indonesia Nomor 22 Tahun 1999 Tentang Pemerintahan Daerah (Indonesia, 1999). Desa juga harus melakukan proses pencatatan data dan memberi informasi kegiatannya pada buku administrasi desa seperti yang diatur oleh Peraturan Menteri Dalam Negeri Nomor 32 Tahun 2006 (Kemendagri, 2006). Administrasi desa khususnya kependudukan di Desa Sumbermulyo perlu diperbaiki dan dikembangkan seiring berkembangnya teknologi informasi yang dapat digunakan untuk membantu meningkatkan pelayanan administrasi. 
Selama ini pelayanan administrasi kependudukan oleh pemerintahan di tingkat desa Sumbermulyo Kecamatan Jogoroto Kabupaten Jombang yang dilakukan oleh para perangkat desa seperti: Surat keterangan pindah, pengajuan Kartu Keluarga (KK), pengajuan Kartu Tanda Penduduk (KTP), dan lain sebagainya belum optimal, karena masih bersifat manual dan belum otomasi. Berbeda dengan pelayanan administrasi di tingkat kecamatan yang telah menggunakan Sistem Informasi Administrasi Kependudukan (SIAK), pada pemerintah tingkat desa, khususnya desa Sumbermulyo Kecamatan Jogoroto Kabupaten Jombang belum memiliki sistem informasi yang memadai untuk menunjang pelayanan administrasi tersebut. Pelayanan bersifat manual memiliki arti bahwa dalam melakukan pelayanan administrasi, data yang digunakan mengacu pada data kependudukan seperti KK ataupun KTP yang mungkin bersifat out of date atau tidak valid. Model pelayanan yang bersifat manual tersebut juga hanya memiliki arsip berupa hardcopy, sehingga menyulitkan perekapan pelayanan administrasi yang dilakukan. Sedangkan pelayanan yang bersifat belum otomasi memiliki arti bahwa dalam melakukan penomoran, terutama surat-surat terkadang memiliki nomor surat yang sama atau nomor tersebut tidak tercatat pada agenda surat, sehingga dapat menimbulkan pertanyaan terhadap keabsahan surat tersebut. Otomasi tidak hanya terbatas pada aspek tata persuratan saja, melainkan juga pada pengolahan data yang secara otomatis dilakukan oleh sistem saat pengguna membutuhkan data yang diperlukan.

Sebagai contoh pada saat warga ingin mendapat pelayanan administrasi kependudukan di kantor desa, maka warga harus mendapat surat pengantar dari Ketua Rukun Tetangga (RT). Kemudian surat tersebut dibawa ke kantor desa untuk dilakukan pembuatan surat yang diinginkan. Pada saat pembuatan surat tersebut, maka data yang dimasukkan mengacu pada KK, KTP, atau bahkan hanya pengakuan yang bersangkutan. Setelah surat selesai dibuat, maka terkadang pula pihak perangkat desa lupa untuk memberikan nomor registrasi surat atau memberi nomor registrasi surat yang sama dengan surat lainnya dikarenakan beberapa hal. Pelayanan administrasi oleh perangkat desa tersebut mengakibatkan beberapa hal antara lain: 1) Data menjadi tidak sinkron dan terjadi redundancy (kerangkapan) data, karena data acuan berasal dari KK, KTP yang bersifat out of date, tidak valid atau hanya berdasarkan pengakuan yang bersangkutan; dan 2) Keabsahan surat dipertanyakan karena tidak bernomor, nomor ganda atau tidak valid.

Hal tersebut merupakan salah satu cerminan urgensi dalam mengadopsi konsep otomasi administrasi kependudukan di desa Sumbermulyo dalam rangka peningkatan pelayanan administrasi yang sesuai dengan kebutuhan warganya. Selain itu konsep otomasi administrasi kependudukan juga sangat berperan penting dalam pelaporan kependudukan semisal data demografi. Data demografi sangat dibutuhkan dalam menunjang keputusan dalam rangka pembangunan desa secara tepat, apalagi saat ini dana yang dialokasi untuk pembangunan desa sangatlah besar. Sebagai contoh pelaporan data demografi antara lain pelaporan tingkat kelahiran, pelaporan data kematian, pelaporan pindah datang, pelaporan jumlah penduduk usia sekolah, pelaporan rasio KK per wilayah desa, dan lain sebagainya. Pelaporanpelaporan tersebut berguna untuk pemetaan pembangunan fasilitas publik di desa, pembangunan sekolah baru, dan pembangunan infrastruktur desa lainnya. Beberapa pemaparan akan pentingnya memiliki sistem informasi otomasi administrasi kependudukan di atas, dapat menjadi acuan dalam membangun sistem tersebut di tingkat desa. Sistem informasi otomasi administrasi kependudukan ini dapat dibangun menggunakan bahasa pemrograman Microsoft Visual Basic.Net 2008 dengan pengolahan data menggunakan database MySQL. Menurut Kusrini dan Koniyo (2007), Sistem informasi akan lebih mudah diolah sehingga berguna dalam mengambil setiap keputusan. Sementara, dengan bahasa pemprograman Microsoft Visual Basic.Net dapat dihasilkan aplikasi yang berbasis GUI (Graphical User Interface), sehinga mudah digunakan. Aplikasi ini berjalan pada platform berbasis Windows yang banyak dipakai orang (Komputer, 2009). Lebih lanjut, Nugroho (2005) menyatakan bahwa dengan menggunakan database MySQL data di database server akan mudah diubah dan dikirim dengan cepat secara multi-user menggunakan Structured Query Language (SQL).

\section{Metode Penelitian}

\subsection{Observasi dan Wawancara}

Untuk mengetahui gambaran umum dan kegiatan administrasi desa Sumbermulyo dilakukan pengamatan di kantor desa. Pengamatan yang dilakukan sebatas pada situasi kerja aparat desa dalam melayani administrasi kependudukan warga dan mencatat data administrative, seperti geografis dan

52 | Register: Jurnal Ilmiah Teknologi Sistem Informasi, Juli 2016, Volume 2, Nomor 2 
demografis. Sementara wawancara dilakukan dengan para perangkat desa setempat untuk mengetahui proses pelayanan administrasi kependudukan. Hal ini dilakukan untuk mendapat data yang lebih lengkap, akurat dan sesuai dengan kebutuhan.

\subsection{Pemodelan}

Analisa perancangan sistem perlu dilakukan untuk dapat membuat aplikasi yang sesuai dengan kebutuhan pelayanan administrasi di desa Sumbermulyo. Menurut Mustakini (2005) perancangan sistem yang baik bertujuan agar dapat memenuhi kebutuhan pemakai sistem tersebut. Selain itu dapat memberikan gambaran yang jelas dan lengkap mengenai rancang bangun sistem yang akan dibuat bagi pembuat program/programmer. Kedua tujuan ini lebih berfokus pada perancangan atau desain sistem yang terinci, yaitu pembuatan rancang bangun yang jelas dan lengkap, yang nantinya digunakan untuk pembuatan program komputernya.

Agar mempermudah perancangan sistem diperlukan pemodelan yang dapat menggambarkan hubungan antar sistem dengan pengguna. Untuk itu, pemodelan perancangan sistem di desa Sumbermulyo digunakan Unified Modeling Language (UML), yang merupakan bahasa pemodelan dengan menggunakan diagram dan teks-teks pendukung. Pemodelan ini adalah yang paling sukses dari tiga pemodelan $\mathrm{OO}$ (Object Oriented) yang telah ada sebelumnya, yaitu Booch, OMT (Object Modeling Technique) dan OOSE (Object Oriented Software Engineering) (Sukamto dan Shalahuddin, 2011). UML diaplikasikan untuk maksud dan tujuan tertentu yaitu (Sukamto dan Shalahuddin, 2011):

1. Merancang perangkat lunak.

2. Sarana komunikasi antara perangkat lunak dengan proses bisnis.

3. Menjabarkan Sistem secara rinci untuk analisa dan mencari apa yang diperlukan oleh sistem.

4. Mendokumentasikan sistem yang ada, proses-proses dan organisasinya.

Dalam pemodelan sistem informasi administrasi di desa Sumbermulyo dengan metode UML digunakan empat macam diagram:

1. Use Case yaitu diagram untuk mendeskripsikan interaksi antara satu atau lebih user dengan sistem.

2. Activity Diagram yaitu diagram yang menggambarkan Workflow (aliran kerja) atau aktivitas dari sebuah sistem.

3. Sequence Diagram yaitu diagram yang menggambarkan kelakuan (behavior) objek pada Use Case dengan mendeskripsikan waktu hidup objek dan pesan yang dikirimkan dan diterima antar objek

4. Class Diagram yaitu diagram yang menggambarkan struktur sistem dari segi pendefinisian kelaskelas yang akan dibuat untuk membangun sistem

\subsection{Pemprograman}

Bahasa pemprograman Microsoft Visual Basic.Net yang digunakan dalam membuat sistem informasi di desa Sumbermulyo mampu mempermudah proses pemprograman. Hal ini disebabkan bahasa pemprograman ini akan bekerja setelah ada respon dari user berupa event/kejadian tertentu (seperti tombol di-klik, menu dipilih, memasukkan data pada text field, dan lain sebagainya) atau dikenal dengan Event Driven Programming (Komputer, 2009).

Sementara untuk kebutuhan menyimpan dan mengolah data digunakan bahasa pemrograman MySQL yang memiliki banyak kelebihan sesuai dengan kebutuhan sistem informasi di desa Sumbermulyo. Misalnya: Berlisensi free/open Source, mampu berperan sebagai database server maupun client, mampu menyimpan data berkapasitas besar, menggunakan enkripsi password untuk sistem keamanannya, dan mendukung multi-user (Komputer, 2009).

\section{Hasil dan pembahasan}

\subsection{Analisis Organisasi}

Hasil observasi lapangan didapat beberapa data antara lain: Data geografis, demografis, struktur organisasi, dan lain sebagainya. Secara geografis desa Sumbermulyo adalah sebuah desa yang masuk pada wilayah kecamatan Jogoroto kabupaten Jombang propinsi Jawa Timur yang memiliki luas wilayah sebesar 449.685 ha. Wilayah tersebut yang terdiri dari luas tanah pertanian sebesar 180 ha dan luas tanah 
kas desa sebesar 449.505 ha. Desa Sumbermulyo terdiri dari 6 Dusun yaitu Sumbermulyo, Semanding, Sidowaras, Bapang, Kebun Mlati, dan Subentoro.

Data demografi yang didapatkan berdasarkan laporan akhir kependudukan desa Sumbermulyo menyebutkan bahwa, penduduk aktif berjumlah 11.658 jiwa yang terdiri dari 5.661 jiwa berjenis kelamin laki-laki dan 5.997 jiwa berjenis kelamin perempuan, adapun data dapat dilihat pada Tabel 1. Sedangkan, struktur organisasi dapat dilihat pada Gambar 1.

Tabel 1 Laporan Demografi Penduduk berdasarkan umur

\begin{tabular}{clcccccc}
\hline \multirow{2}{*}{ No. } & \multirow{2}{*}{ Dusun } & \multicolumn{5}{c}{ Umur (tahun) } & \multirow{2}{*}{ Jumlah } \\
\cline { 3 - 7 } & & $\mathbf{< 5}$ & $\mathbf{5 - 1 2}$ & $\mathbf{1 3 - 1 8}$ & $\mathbf{1 9}-\mathbf{5 0}$ & $\boldsymbol{>} \mathbf{5 0}$ & \\
\hline 1 & Sumbermulyo & 131 & 588 & 442 & 2339 & 737 & $\mathbf{4 2 3 7}$ \\
2 & Semanding & 67 & 313 & 244 & 1177 & 340 & $\mathbf{2 1 4 1}$ \\
3 & Sidowaras & 51 & 189 & 143 & 738 & 190 & $\mathbf{1 3 1 1}$ \\
4 & Bapang & 43 & 179 & 119 & 605 & 151 & $\mathbf{1 0 9 7}$ \\
5 & Kebun Mlati & 56 & 201 & 160 & 856 & 214 & $\mathbf{1 4 8 7}$ \\
6 & Subentoro & 60 & 194 & 168 & 741 & 222 & $\mathbf{1 3 8 5}$ \\
& Jumlah & $\mathbf{4 0 8}$ & $\mathbf{1 6 6 4}$ & $\mathbf{1 2 7 6}$ & $\mathbf{6 4 5 6}$ & $\mathbf{1 8 5 4}$ & $\mathbf{1 1 6 5 8}$ \\
\hline
\end{tabular}

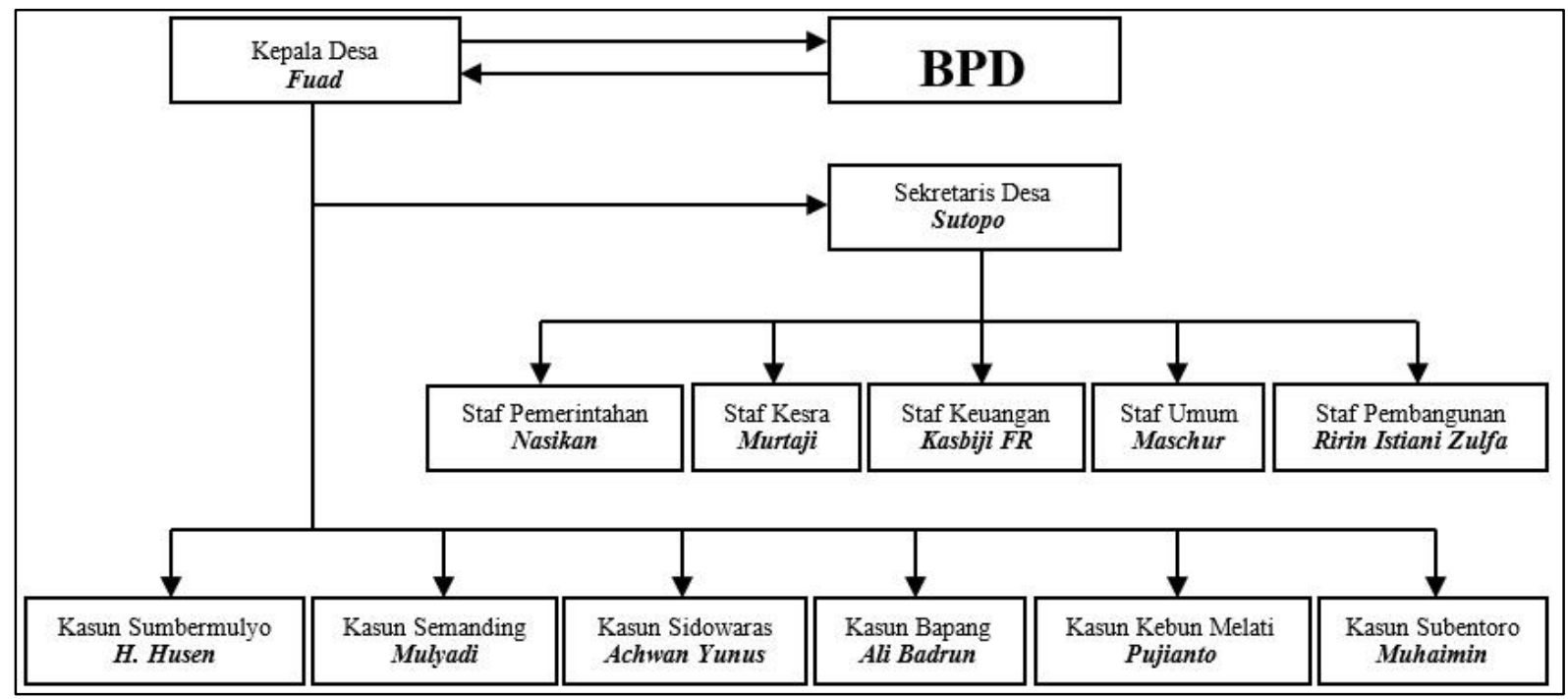

Gambar 1 Struktur Organisasi Desa Sumbermulyo Kecamatan Jogoroto Kabupaten Jombang

\subsection{Analisis Kebutuhan Data}

Proses pelayanan administrasi didapat saat melakukan wawancara dengan para perangkat desa, kemudian data hasil observasi dan wawancara tersebut dianalisis, sehingga didapatkan kesimpulan bahwa Desa Sumbermulyo membutuhkan data antara lain:

1. Data Wilayah

Data wilayah merupakan data yang berisi data wilayah dari desa Sumbermulyo, mulai dari tingkat atas yang meliputi: Propinsi, kabupaten, dan juga tingkat bawah yang meliputi dusun.

2. Data Induk Kependudukan

Data Induk Kependudukan adalah data mengenai registrasi penduduk pada Kartu Keluarga (KK).

3. Data Penduduk

Data Penduduk merupakan induk data warganegara baik WNI (Warga Negara Indonesia) maupun WNA (Warga Negara Asing) yang ada di desa Sumbermulyo. Data penduduk ini dirancang secara dinamis untuk mengantisipasi terjadinya perubahan aturan pencatatan dalam kependudukan. Misal data pekerjaan, saat ini secara resmi dalam aturan kependudukan macam kelompok pekerjaan sebanyak 89 . Tidak hanya kelompok pekerjaan, data pendukung lainnya juga dirancang sedinamis mungkin. Data tersebut antara lain Agama, Akseptor KB, Golongan Darah, Status Hubungan dalam Keluarga, Kelainan Khusus, dan Pendidikan.

54 | Register: Jurnal Ilmiah Teknologi Sistem Informasi, Juli 2016, Volume 2, Nomor 2 
Setelah Kebutuhan data terpenuhi, maka sistem dapat melakukan proses pengolahan terhadap data tersebut yang dapat menghasilkan output yang diharapkan antara lain:

1. Data Administrasi

Data Administrasi adalah data meliputi segala administrasi yang dapat ditangani oleh sistem. Sebagai contoh: Surat Keterangan Pindah Datang, Surat Keterangan Kematian, Surat Model N untuk pernikahan, Data Tempat Ibadah, dan lain sebagainya.

2. Data Hasil Pengolahan

Data Hasil Pengolahan merupakan sebuah hasil dari data yang diolah dengan metode atau kriteria tertentu sehingga dapat memenuhi kebutuhan informasi yang diperlukan oleh pengguna. Contoh Data Pemilih Sementara (DPS), Data Pemilih Tetap (DPT), analisis tingkat kematian dan kelahiran, dan lain sebagainya.

3. Pelaporan

Pelaporan ini meliputi antara lain Laporan Penduduk Akhir Periode, Pelaporan Kematian dan Kelahiran dalam Periode tertentu, Grafik jumlah layanan tata persuratan, laporan pindah dating, dan lain sebagainya.

\subsection{Analisis Infrastruktur Sistem}

Setelah melakukan analisis kebutuhan yang lebih banyak membahas pada data, maka kemudian dilakukanlah analisa terhadap infrastruktur yang digunakan oleh sistem nantinya. Sistem yang dibangun ditempatkan dibeberapa tempat. Mulai dari Balai Desa sebagai tempat pelayanan utama, RT sebagai tempat layanan administrasi awal, dan yang terakhir sebagai pemantau layanan administrasi. Pada lokasi pertama dan kedua, aplikasi yang dibangun berupa aplikasi desktop. Khusus pada lokasi ketiga sebagai pemantau administrasi, platform yang digunakan adalah mobile, sehingga dapat digunakan di mana saja. Platform mobile yang dimaksud hanya berupa aplikasi mobile yang berfungsi untuk memantau saja dan tidak memiliki fungsi melakukan layanan administrasi.

Untuk dapat menangani semua platform tersebut, maka server dibangun secara terpisah yang dapat diakses secara online oleh beberapa platform sistem yang berbeda secara real time sehingga secara keseluruhan, sistem yang dibangun bersifat Client Server.

\subsection{Analisis Portofolio Aplikasi}

Dalam membangun sistem informasi yang dapat mengotomasi administrasi desa beserta dengan infrastruktur sistemnya, maka dibutuhkan analisa terhadap letak sistem yang dibangun tersebut pada portofolio aplikasi. Portofolio yang diadopsi adalah matriks Mcfarlan yang terdiri dari 4 kuadran (Ward, 2002) yaitu:

1. Kuadran Strategic

Pada kuadran ini berisi aplikasi yang memiliki peranan penting akan kelangsungan proses utama yang dilakukan untuk mencapai tujuan akhir.

2. Kuadran Key Operational segala sesuatu yang menopang akan proses operasional yang dilakukan aplikasi pada kuadran strategic.

Pada kuadran ini berisi aplikasi yang

3. Kuadran Support

Kuadran yang berisi segala sesuatu yang dapat mengefisiensikan proses utama, akan tetapi tidak memberikan keuntungan.

4. Kuadran High Potential

Kuadran yang berisi aplikasi yang kemungkinan di masa mendatang memiliki pengaruh, seperti aplikasi yang ada pada kuadran strategic, walaupun saat ini belum terlalu berpengaruh.

Sehingga berdasarkan analisa tersebut, maka portofolio dapat digambarkan pada Tabel 2.

\subsection{Rancangan Sistem}

Dengan menggunakan pemodelan use case diagram didapat beberapa diagram yang dapat membantu mendeskripsikan fungsi-fungsi sistem secara garis besar. Diagram tersebut antara lain: use case Data Master, use case data Induk Kependudukan, use case Data administrasi, dan lain sebagainya. Salah satu contoh diagram use case dapat dilihat pada Gambar 2 yaitu use case Data Master. 
Kemudian melalui pemodelan activity diagram dihasilkan diagram untuk menggambarkan urutan aktivitas pada suatu proses antara actor admin/user, sistem dan database. Urutan aktivitas tersebut untuk mendeskripsikan hubungan antar aktor pada saat aktivitas.

1. Login

2. Pengolahan data master, kelompok pekerjaan, data penduduk, KK, biodata, Surat Keterangan

Catatan Kepolisian (SKCK), surat pindah datang dan lain sebagainya

3. Pencarian umum maupun data khusus dengan kriteria tertentu

4. Cetak data, cetak daftar kartu keluarga, cetak surat

5. Pengaturan user dan hak aksesnya

6. Import dan back up.

Tabel 2 Portofolio Aplikasi

\begin{tabular}{ll}
\hline \multicolumn{1}{c}{ Strategic } & \multicolumn{1}{c}{ High Potential } \\
\hline - Sistem Informasi Otomasi Administrasi & - Sistem Informasi Tanah \\
Kependudukan & - Sistem Informasi Badan Usaha Milik Desa \\
\hline \multicolumn{1}{c}{ Key Operational } & \multicolumn{1}{c}{ Support } \\
\hline - Undang-Undang & \\
- Peraturan Daerah & - Data Kependudukan \\
- Standar Layanan & \\
- SOP (Standart Operating Procedure) & \\
\hline
\end{tabular}

Contoh hasil pemodelan activity diagram pada Gambar 2 menunjukan aktivitas admin dengan sistem pada data KK.

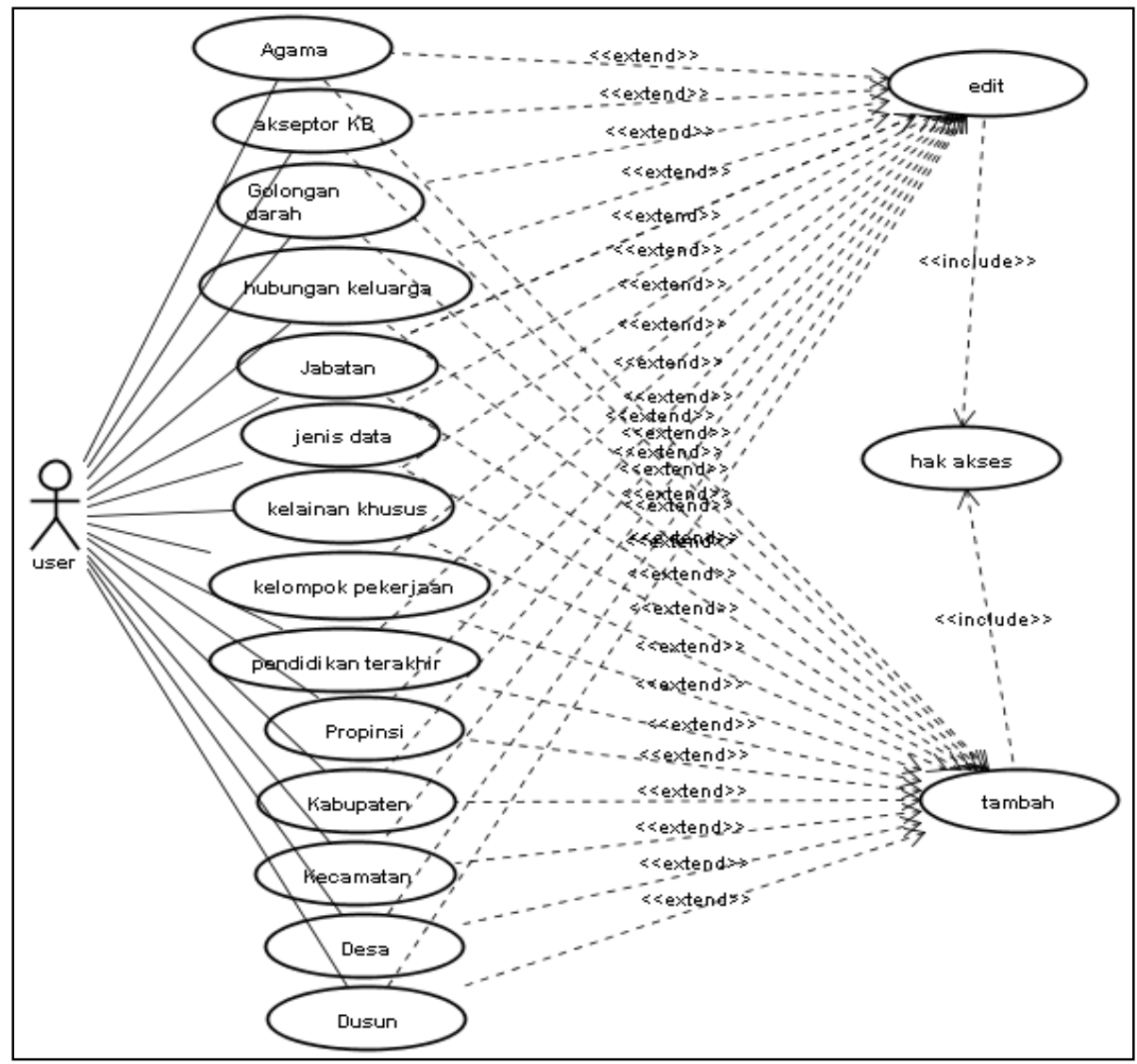

Gambar 2 Use Case Data Master dengan actor user

Selanjutnya pemodelan sequence diagram menghasilkan diagram untuk menggambarkan urutan interaksi antara sejumlah object dalam suatu aktivitas. Urutan interaksi sejumlah objek tergambar dalam aktivitas: login, tambah data kelompok pekerjaan oleh admin, edit data kelompok pekerjaan oleh admin, hapus data kelompok pekerjaan oleh admin, tambah data kelompok pekerjaan oleh user, edit data

56 | Register: Jurnal Ilmiah Teknologi Sistem Informasi, Juli 2016, Volume 2, Nomor 2 
kelompok pekerjaan oleh user, tambah data KK oleh admin, edit data KK oleh admin, hapus data KK oleh admin, tambah data KK oleh user, edit data KK oleh user, tambah data SKCK oleh admin, tambah data SKCK oleh admin, tambah data hak akses oleh admin, edit data hak akses oleh admin, dan hapus data hak akses oleh admin.

Pemodelan yang terakhir yang digunakan dalam membuat sistem informasi ini adalah pemodelan class diagram. Pemodelan ini menghasilkan diagram Entity Relationship Diagram (ERD) seperti yang digunakan dalam basis data, hanya saja pemodelan ini fokus bukan pada data saja, tetapi juga pada prilaku sistem. Diagram yang dihasilkan dengan pemodelan ini adalah: Class Diagram Biodata dan Class Diagram Surat.

Setelah melakukan pemprograman menggunakan bahasa pemprograman Microsoft Visual Basic.Net 2008 dengan pengolahan data menggunakan MySQL hal yang tak kalah pentingnya adalah merancang antarmuka pemakai (user interface). Hal ini dilakukan agar sistem informasi yang telah dibuat dan berjalan pada sistem komputer dapat digunakan oleh manusia dengan mudah baik untuk memasukan data, melihat data maupun mencetak laporan. Gambar 3 berikut adalah rancangan antarmuka halaman utama.

\section{Implementasi}

Tahap implementasi merupakan tahap yang sangat penting. Sebaik apapun sistem informasi jika gagal dalam implementasi maka akan menjadi tidak berguna. Agustiawan (2011), menyimpulkan dari beberapa hasil riset yang dilakukan oleh Chaos Report (1995), OASIG Study (1995), KPMG Canada Survey (1997), dan The Bull Survey (1998) terlihat bahwa meskipun faktor utama kegagalan sistem informasi adalah sistem itu sendiri namun lingkungan internal organisasi seperti sumber daya manusia berupa kemampuan menguasai teknologi; manajemen berupa kurangnya perencanaan, pelaksanaan dan pengawasan maupun prilaku dalam berorganisasi berupa komunikasi dan koordinasi juga mempunyai peranan yang cukup signifikan.

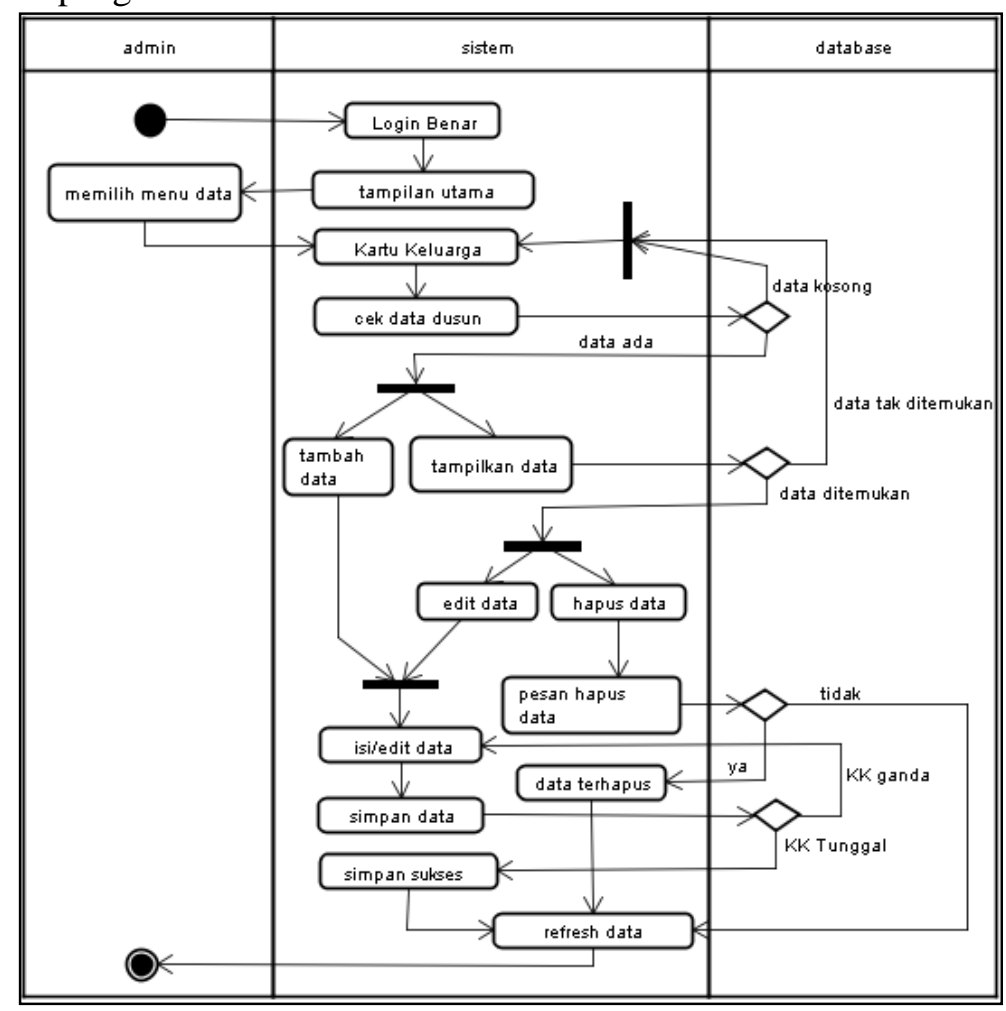

Gambar 3 Activity Diagram Kartu Keluarga

Pada implementasi sistem informasi administrasi ini digunakan perangkat keras berupa: Komputer dengan spesifikasi Intel ${ }^{\circledR}$ Core $^{\mathrm{TM}} \mathrm{i} 3-2330 \mathrm{M}$ CPU @ $2.20 \mathrm{Ghz}$, memory $2.00 \mathrm{~Gb}$, hardisk 160 $\mathrm{Gb}$, kartu grafis $256 \mathrm{Mb}$. Sementara perangkat lunak yang digunakan berupa; sistem operasi: Microsoft Windows 8, database: MySQL versi 5.5.16, dan bahasa pemrograman: Microsoft Visual Basic.Net 2008. 
Implementasi di tingkat organisasi desa dilakukan dengan melakukan pelatihan pengenalan dan penggunaan kepada aparat desa bagaimana menggunakan sistem administrasi kependudukan ini. Aparat desa dibagi menjadi dua pengguna yaitu sebagai administrator atau admin dan sebagai pengguna biasa atau $u$ ser.

Sebagai admin maka pengguna memiliki semua hak akses misalnya mengisi dan merubah master data pekerjaan, agama, hubungan keluarga dan lain-lain. Gambar 4 berikut adalah menu yang hanya bisa diakses oleh admin. Sedangkan hak akses user terbatas pada fungsi-fungsi tertentu saja misalnya menu pelayanan administrasi kependudukan seperti surat pindah, kelahiran, kartu keluarga (KK), dan lain-lain serta pencetakan pelaporan. Contoh menu yang bias digunakan oleh user dapat dilihat pada Gambar 5. Salah satu tampilan aplikasi yang sudah jadi ditampilkan pada Gambar 6.

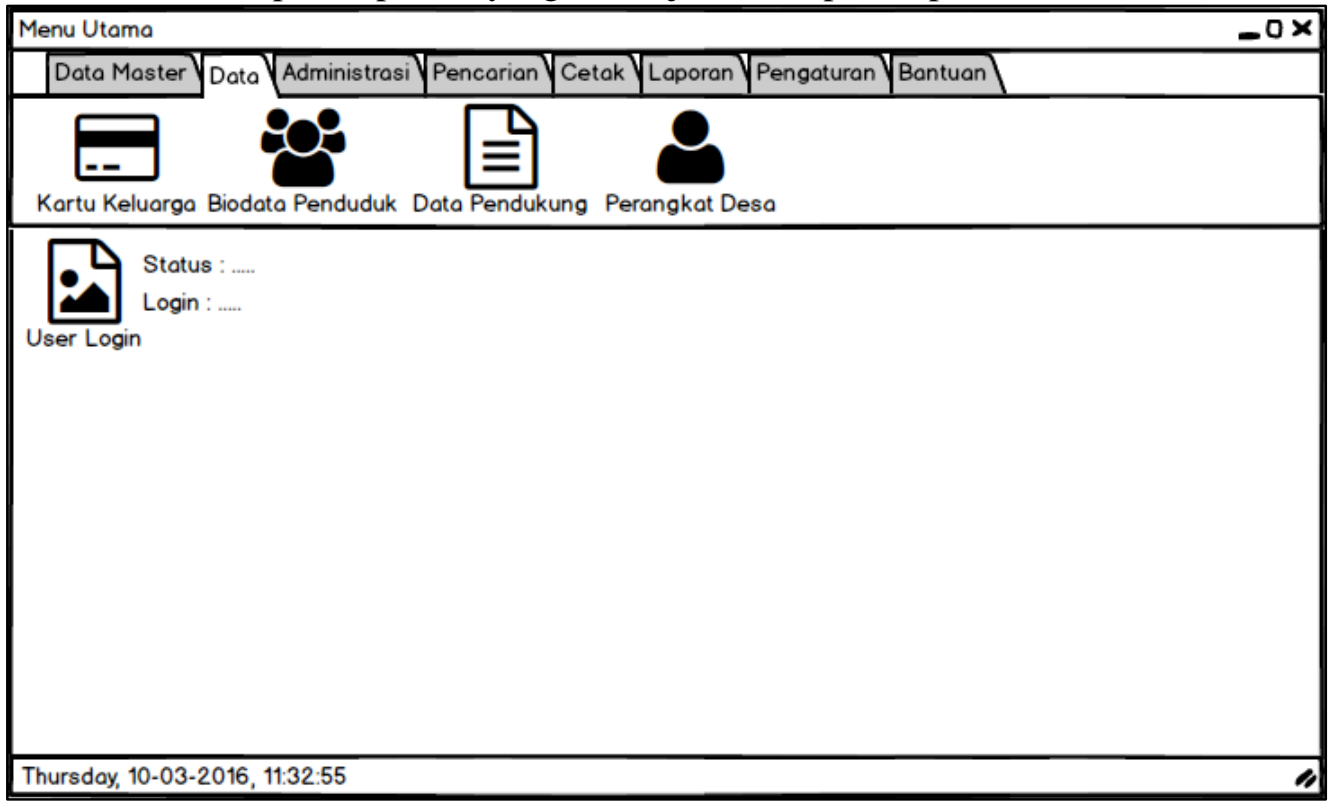

Gambar 4 Antarmuka halaman utama

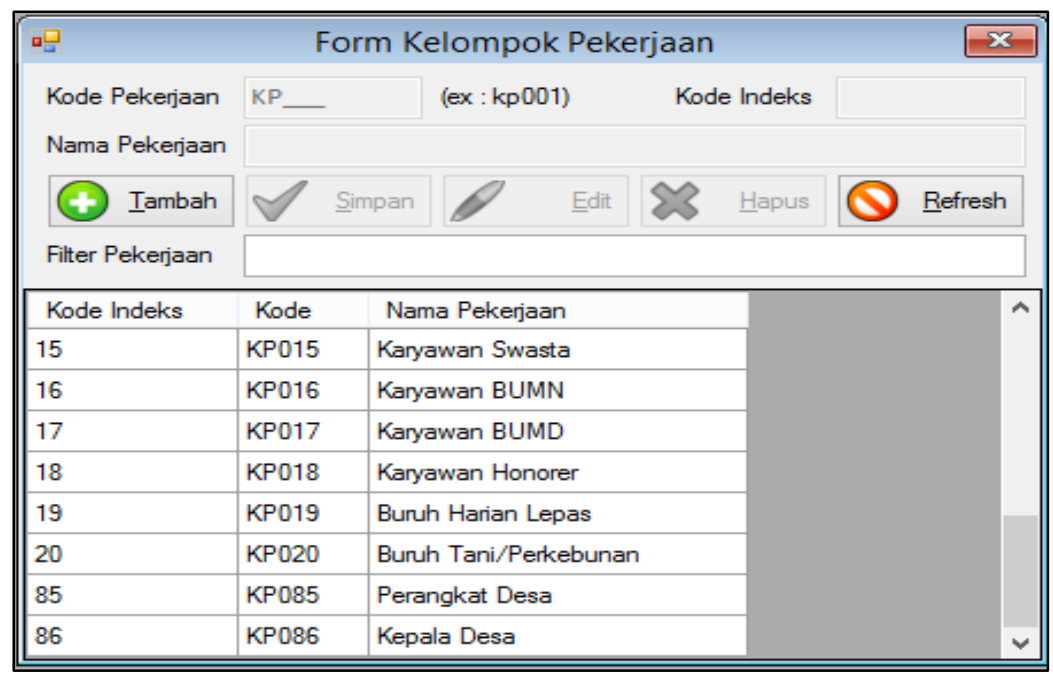

Gambar 5 Menu Data Pekerjaan

\section{Kesimpulan}

Peningkatan pelayanan administrasi di desa Sumbermulyo perlu dilakukan mengingat pelayanan administrasi di ana masih bersifat manual dan belum terotomasi, sehingga sering menyebabkan redudansi dan ketidaksinkronan antar data. Upaya ini dapat dilakukan dengan membuat sebuah sistem informasi administrasi. Bahasa pemrograman Microsoft Visual Basic.Net 2008 dengan pengolahan database menggunakan MySQL dapat digunakan untuk keperluan tersebut. Proses perancangan dalam pembuatan sistem informasi ini

58 | Register: Jurnal Ilmiah Teknologi Sistem Informasi, Juli 2016, Volume 2, Nomor 2 
menggunakan metode Unified Modeling Language (UML) dengan menggunakan empat macam diagram; use case, activity, sequence dan class diagram. Sistem informasi ini masih berupa sistem informasi kependudukan sehingga perlu dikembangkan pada administrasi desa secara menyeluruh yang meliputi administrasi keuangan desa, administrasi pembangunan dan administrasi Badan Permusyawaratan Desa (BPD). Lebih lanjut, mengingat sistem informasi ini juga masih bersifat standalone atau tersimpan secara tersendiri di satu komputer maka pengembangan ke arah cloud computing berbasis web akan dapat meningkatkan flexibilitasnya.

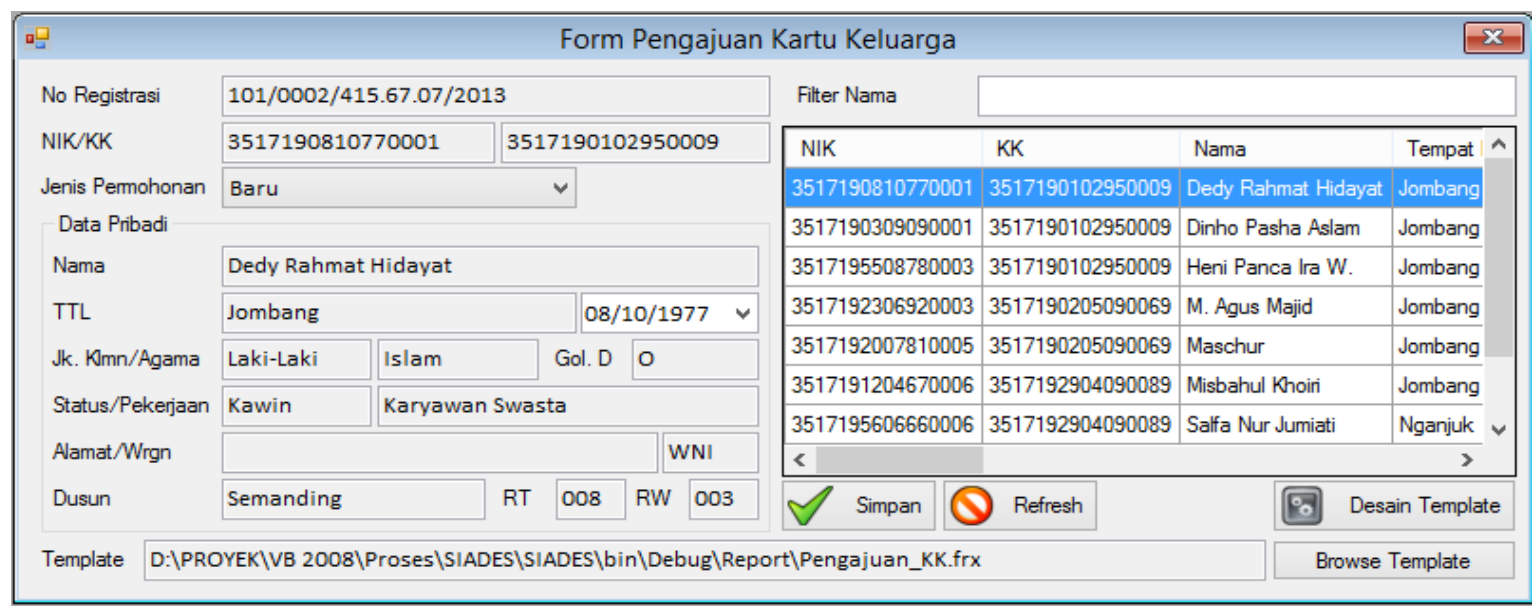

Gambar 6 Menu Isian Permohonan KK

\section{Referensi}

Agustiawan, Y. (2011). Perubahan Dalam Organisasi Pada Implementasi Sistem Informasi. Teknologi, l(2), 110-116.

Indonesia, R. (1999). Undang-Undang No.22 Tahun 1999 tentang Pemerintahan Daerah. Jakarta, Jakarta, Indonesia.

Indonesia, R. (2014). Undang-Undang No 6 Tahun 2014 tentang Desa. Jakarta, Jakarta, Indonesia.

Kemendagri. (2006, Oktober 10). Permendagri Nomor 30 tahun 2006 Tentang Tatacara Penyerahan Urusan Pemerintahan Kabupaten dan Kota Kepada Desa . Jakarta, Jakarta, Indonesia.

Komputer, W. (2009). Membangun Aplikasi Toko dengan Visual Basic 2008. Yogyakarta: Andi.

Kusrini, \& Koniyo, A. (2007). Tuntunan Praktis Membangun Sistem Informasi Akuntansi dengan Visual Basic \& Microsoft SQL Server. Yogyakarta: Andi.

Mustakini, J. H. (2005). Analisis dan Desain Sistem Informasi: Pendekatan terstruktur teori dan praktek aplikasi bisnis. Yogyakarta: Andi.

Nugroho, B. (2005). Database Relasional Dengan MySQL. Yogyakarta: Andi.

Sukamto, R. A., \& Shalahuddin, M. (2011). Rekayasa Perangkat Lunak Terstruktur dan Berorientasi Objek. Bandung: Modula.

Ward, J. and J. Peppard. (2002). Strategic Planning for Information System. $3^{\text {rd }}$ edition. West Sussex: John Wiley \& Sons. 